\title{
KAITAN SPEKTRUM KETETANGGAAN DARI GRAF SEKAWAN
}

\author{
DWI HARYANINGSIH \\ Program Studi Matematika, \\ Fakultas Matematika dan Ilmu Pengetahuan Alam, Universitas Andalas, \\ Kampus UNAND Limau Manis Padang, Indonesia, \\ haryadwiyanie@yahoo.co.id
}

\begin{abstract}
Abstrak. Suatu graf $G$ dapat ditentukan oleh spektrum ketetanggaannya jika tidak ada graf non isomorfik lain dengan spektrum ketetanggaan yang sama. Pada tulisan ini dikaji kembali makalah [4] tentang kaitan spektrum ketetanggaan dari graf sekawan.

Kata Kunci: Matriks ketetanggaan, graf sekawan, spektrum
\end{abstract}

\section{Pendahuluan}

Misalkan terdapat graf $G=(V, E)$ dengan $|V(G)|=n$. Titik $v_{i}$ dan $v_{j}$ di $V(G)$ dikatakan bertetangga jika $v_{i} v_{j} \in E(G)$. Matriks ketetanggaan $A(G)=\left(a_{i j}\right)$ didefinisikan sebagai matriks berukuran $n \times n$, dimana

$$
a_{i j}=\left\{\begin{array}{l}
1, \text { titik } v_{i} \text { bertetangga dengan } v_{j}, \\
0, \text { titik } v_{i} \text { tidak bertetangga dengan } v_{j} .
\end{array}\right.
$$

Nilai-nilai eigen dari $A(G)$, dinotasikan $\lambda_{1}(G), \lambda_{2}(G), \cdots, \lambda_{s}(G), s \leq n$, adalah solusi dari persamaan karakteristik $0=\operatorname{det}(\lambda I-A(G))$, dimana $I$ adalah matriks identitas dengan ukuran $n \times n$. Multiplisitas aljabar dari $\lambda_{i}(G)$ adalah banyaknya nilai eigen $\lambda_{i}(G)$ yang muncul dari persamaan karakteristik, dinotasikan dengan $m\left(\lambda_{i}(G)\right), 1 \leq i \leq s$. Spektrum dari matriks ketetanggaan $A(G)$, dinotasikan dengan $\operatorname{Spec}(A(G))$, didefinisikan sebagai matriks berukuran $2 \times s, s \leq n$ yang berisikan semua nilai eigen dari $A(G)$ beserta multiplisitas aljabarnya sebagai berikut.

$$
\operatorname{spec}(A(G))=\left(\begin{array}{cccc}
\lambda_{1} & \lambda_{2} & \cdots & \lambda_{s} \\
m\left(\lambda_{1}\right) & m\left(\lambda_{2}\right) & \cdots & m\left(\lambda_{s}\right)
\end{array}\right) .
$$

Dalam [6], Wang dkk. memberikan dugaan terkait spektrum ketetanggaan dari graf sekawan $F_{t}$ sebagai berikut.

Dugaan 1.1. [6] Suatu graf $G$ adalah graf sekawan $F_{t}$ jika dan hanya jika tidak ada graf lain dengan

$$
\operatorname{spec}(G)=\left(\begin{array}{cccc}
\frac{1+\sqrt{1+8 t}}{2} & 1 & -1 & \frac{1-\sqrt{1+8 t}}{2} \\
1 & t-1 & t & 1
\end{array}\right),
$$

selain graf sekawan. 
Dalam [4], Das dkk. menunjukkan bahwa dugaan tersebut adalah benar. Pada tulisan ini akan dikaji tentang pembuktian kebenaran dugaan tersebut.

\section{Beberapa Konsep Pendukung}

Dalam [7], Schott menunjukkan bahwa apabila terdapat matriks simetri $B$ berukuran $p \times p$ dan $B_{k}$ adalah submatriks $k \times k$, dimana $B_{k}$ adalah matriks yang diperoleh dari $B$ dengan menghapus baris dan kolom ke $i$ hingga $p$ terakhir pada $p-k$, maka untuk $i=1,2, \cdots, k$, berlaku:

$$
\lambda_{p-i+1}(B) \leq \lambda_{k-i+1}\left(B_{k}\right) \leq \lambda_{k-i+1}(B),
$$

dimana $\lambda_{i}(B)$ adalah nilai eigen terbesar ke $i$ di $B$.

Dalam [5], Das memperoleh bahwa apabila $G$ adalah graf sederhana dengan orde $n$, yang memiliki $t$ buah segitiga, maka:

$$
\sum_{v_{i} v_{j} \in E(G)}\left|N_{i} \bigcap N_{j}\right|=3 t
$$

dimana $\left|N_{i} \bigcap N_{j}\right|$ adalah kardinalitas dari tetangga bersama (common neighbor) dari titik-titik $v_{i}$ dan $v_{j}$.

Lema 2.1. [4] Misalkan graf $G$ adalah suatu graf terhubung dengan t buah segitiga. Jika setiap sisi termuat dalam tepat satu segitiga di $G$, maka banyaknya titik di $G$ adalah $2 t+1$.

Bukti. Misalkan $n$ adalah banyaknya titik di graf $G$. Karena $G$ terhubung, mempunyai $t$ buah segitiga dan setiap sisi termuat dalam tepat satu segitiga di $G$, maka banyak sisi $G$ adalah $m=3 t$. Karenanya, $m=3 t=n+t-1$. Sehingga diperoleh $n=2 t+1$.

\section{Kaitan Spektrum Ketetanggaan dari Graf Sekawan}

Das dkk. [4] memberikan bukti bahwa Dugaan 1.1 (Wang dkk. [6]) adalah benar seperti yang tercantum dalam Teorema 3.1 berikut.

Teorema 3.1. [4] Suatu graf $G$ adalah graf sekawan $F_{t}$ jika dan hanya jika tidak ada graf lain dengan

$$
\operatorname{spec}(G)=\left(\begin{array}{cccc}
\frac{1+\sqrt{1+8 t}}{2} & 1 & -1 & \frac{1-\sqrt{1+8 t}}{2} \\
1 & t-1 & t & 1
\end{array}\right),
$$

selain graf sekawan.

Bukti. Pada Gambar 1 diberikan graf sekawan $F_{t}$ dengan

$$
\begin{aligned}
& V\left(F_{t}\right)=\left\{c, x_{1}, x_{2}, \cdots, x_{2 t-1}, x_{2 t}\right\}, \\
& E\left(F_{t}\right)=\left\{c x_{i} \mid 1 \leq i \leq 2 t\right\} \cup\left\{x_{i} x_{i+1} \mid i=1,3, \cdots, 2 t-1\right\} .
\end{aligned}
$$

Dapat diperoleh bahwa spektrum ketetanggaan dari graf sekawan $F_{t}$ adalah: 


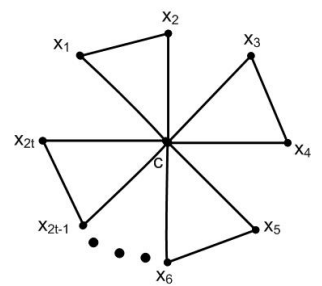

$F_{t}$

Gambar 1. Graf sekawan $F_{t}$.

$$
\operatorname{spec}\left(F_{t}\right)=\left(\begin{array}{cccc}
\frac{1+\sqrt{1+8 t}}{2} & 1 & -1 & \frac{1-\sqrt{1+8 t}}{2} \\
1 & t-1 & t & 1
\end{array}\right) .
$$

Andaikan terdapat graf lain, namakan graf $G$ dengan $|V(G)|=n$, yang mempunyai spektrum ketetanggaan yang sama dengan $F_{t}$. Maka $|V(G)|=n=2 t+1$ dan

$$
\operatorname{spec}(G)=\left(\begin{array}{cccc}
\frac{1+\sqrt{1+8 t}}{2} & 1 & -1 & \frac{1-\sqrt{1+8 t}}{2} \\
1 & t-1 & t & 1
\end{array}\right) .
$$

Diperoleh:

$$
\begin{aligned}
& \sum_{i=1}^{n} \lambda_{i}(G)=0, \\
& \sum_{i=1}^{n} \lambda_{i}^{2}(G)=6 t, \\
& \sum_{i=1}^{n} \lambda_{i}^{3}(G)=6 t .
\end{aligned}
$$

Akan ditunjukkan bahwa haruslah $G \cong F_{t}$. Untuk setiap $G$ berlaku:

$$
\begin{aligned}
0 & =\sum_{i=1}^{n} \lambda_{i}(G) \\
& =0 \\
6 t & =\sum_{i=1}^{n} \lambda_{i}^{2}(G) \\
& =2 m, \\
6 t & =\sum_{i=1}^{n} \lambda_{i}^{3}(G) \\
& =2 \sum_{v_{j} v_{i} \in E(G)}\left|N_{i} \bigcap N_{j}\right| .
\end{aligned}
$$

Berdasarkan pertidaksamaan (2.2) diperoleh bahwa:

$$
\sum_{v_{i} v_{j} \in E(G)}\left|N_{i} \bigcap N_{j}\right|=3 t .
$$


Jadi, $|V(G)|=n=2 t+1$ dan $|E(G)|=3 t$, dengan banyaknya segitiga adalah $t$.

Untuk $t=1$, graf $G$ mempunyai $n=3$ titik, $m=3$ sisi dan satu buah segitiga yaitu $t=1$. Oleh karena itu, haruslah $G \cong F_{1}$.

Untuk $t=2$, graf $G$ mempunyai $n=5$ titik dan $m=6$ sisi, serta dua buah segitiga. Terdapat tiga kemungkinan graf $G$ dengan lima titik dan enam sisi yang punya dua buah segitiga, yaitu graf $G \cong F_{2}, G \cong G_{2}$, dan $G \cong G_{3}$ pada Gambar 2 .

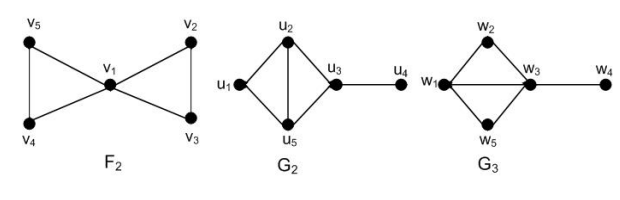

Gambar 2. Graf $F_{2}, G_{2}$ dan $G_{3}$

Persamaan karakteristik dari $F_{2}, G_{2}$, dan $G_{3}$ adalah:

$$
\begin{aligned}
\lambda^{5}-0 \lambda^{4}-6 \lambda^{3}-4 \lambda^{2}+5 \lambda+4 & =0, \text { untuk graf } F_{2}, \\
\lambda^{5}-0 \lambda^{4}-6 \lambda^{3}-4 \lambda^{2}+3 \lambda+2 & =0, \text { untuk graf } G_{2}, \\
\lambda^{5}-0 \lambda^{4}-6 \lambda^{3}-4 \lambda^{2}+2 \lambda & =0, \text { untuk graf } G_{3} .
\end{aligned}
$$

Sehingga diperoleh:

$$
\begin{aligned}
\operatorname{spec}\left(F_{2}\right) & =\left(\begin{array}{cccc}
\frac{1}{2}+\frac{1}{2} \sqrt{17} & 1 & -1 & \frac{1}{2}-\frac{1}{2} \sqrt{17} \\
1 & 1 & 2 & 1
\end{array}\right), \\
\operatorname{spec}\left(G_{2}\right) & =\left(\begin{array}{ccccc}
2.641 & 0.724 & -0.589 & -1 & -1.776 \\
1 & 1 & 1 & 1 & 1
\end{array}\right) \neq \operatorname{spec}\left(F_{2}\right), \\
\operatorname{spec}\left(G_{3}\right) & =\left(\begin{array}{ccccc}
2.686 & 0.335 & 0 & -1.271 & -1.749 \\
1 & 1 & 1 & 1 & 1
\end{array}\right) \neq \operatorname{spec}\left(F_{2}\right) .
\end{aligned}
$$

Karena $\operatorname{spec}(G)=\operatorname{spec}\left(F_{2}\right), \operatorname{spec}(G) \neq \operatorname{spec}\left(G_{2}\right), \operatorname{spec}(G) \neq \operatorname{spec}\left(G_{3}\right)$, maka untuk $t=2$, haruslah $G \cong F_{2}$.

Selanjutnya, untuk $t \geq 3$, diperoleh $n \geq 7$ dan $m \geq 9$. Pertama-tama diasumsikan bahwa terdapat satu sisi $u v$ yang termuat dalam dua segitiga di $G$. Karena $n \geq 7, m \geq 9$ dan $t \geq 3$, maka dapat diasumsikan $G_{3}$ adalah subgraf dari $G$ atau $G_{4}$ adalah subgraf dari $G$. (lihat Gambar 2 dan Gambar 3).

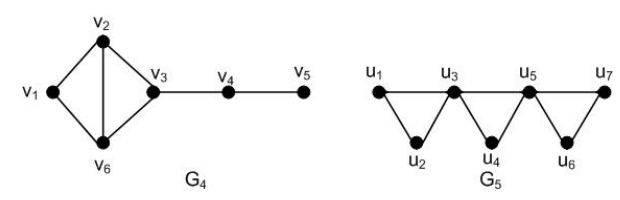

Gambar 3. Graf $G_{4}$ dan $G_{5}$ 
Jika $G_{3}$ adalah subgraf dari $G$, maka berdasarkan pertidaksamaan (2.1), diperoleh bahwa:

$$
-1=\lambda_{4}(G) \leq \lambda_{4}\left(G_{3}\right) \approx-1.271, \text { kontradiksi. }
$$

Jika $G_{4}$ adalah subgraf dari $G$, maka berdasarkan pertidaksamaan (2.1), diperoleh bahwa:

$$
1=\lambda_{2}(G) \geq \lambda_{2}\left(G_{4}\right) \approx 1.211, \text { kontradiksi. }
$$

Selanjutnya diasumsikan bahwa setiap sisi termuat dalam paling banyak satu segitiga di $G$. Karena $G$ memiliki banyak sisi $3 t$ dengan banyak segitiga $t$, maka setiap sisi harus termuat dalam tepat satu segitiga di $G$. Andaikan $G$ mempunyai $r$ buah komponen terhubung yang masing-masingnya terdiri dari $n_{i}$ titik dan $t_{i}$ segitiga dengan $(i=1,2, \cdots, r)$, maka:

$$
\begin{aligned}
n & =\sum_{i=1}^{r} n_{i} \\
& =\sum_{i=1}^{r}\left(2 t_{i}+1\right) \\
& =2 t+r .
\end{aligned}
$$

Tetapi $n=2 t+1$. Maka haruslah $r=1$ dan karenanya, $G$ terhubung. Karena $n=2 t+1, m=3 t$ dengan $t$ buah segitiga dan setiap sisi di $G$ terdapat dalam tepat satu segitiga, maka haruslah $G \cong F_{t}$.

\section{Ucapan Terima kasih}

Penulis mengucapkan terima kasih kepada Ibu Dr. Lyra Yulianti, Ibu Dr. Yanita, Bapak Dr. Admi Nazra, Bapak Prof. Dr. Syafrizal Sy dan Bapak Zulakmal, M. Si yang telah memberikan masukan dan saran sehingga paper ini dapat diselesaikan dengan baik.

\section{Daftar Pustaka}

[1] Anton, H. 1991. Aljabar Linier Elementer Edisi Kedelapan. Jilid 1. Penerbit Erlangga, Jakarta

[2] Biggs, N. 1993. Algebraic Graph Theory. Cambridge University Press, New York

[3] Bondy. J.A, dan Murty, U. S. R. 1976. Graph Theory with Applications. Macmillan, London

[4] Das, K.C. 2013. Proof of conjectures on adjacency eigenvalues of graphs. Discrete Mathematics. 313: 19 - 25

[5] K. C. Das, I. Gutman. 2009. Estimating the Szeged index, Appl. Math. Letter 22: $1680-1684$

[6] J. F. Wang, F. Belardo, Q. X. Huang, B. Borovicanin. 2010. On the two largest Q-eigenvalues of graphs, Discrete Math 310: 2858 - 2866

[7] J. R. Schott. 1997. Matrix Analysis for Statistics. John Wiley and Sons, New York 